\title{
Innovative Thought of Tendering Management Mechanism of Universities and Colleges in China under New Circumstances Taking North China Electric Power University as an Example
}

\section{Ze Zhou}

North China Electric Power University, Baoding, Hebei, 071003, China

\begin{abstract}
Since the reform and opening up, the Chinese government has attached growing importance to education, and has invested more resources and funds into higher education. In addition, the government has also invested large amounts of funds and technologies in the infrastructure construction of universities and colleges. The undertakings related to the infrastructure construction of universities and colleges in China are complicated in essence. Therefore, funds and technologies of the highest standards should be introduced. At the same time, external tendering is necessary for some undertakings. Currently, the tendering model adopted by universities and colleges in China is the traditional, which is ridden with some problems to be resolved in the shortest possible period. This paper focuses on the current problems of the tendering model adopted by universities and colleges and their solutions. Taking the tendering model in the undertakings of North China Electric Power University as an example, it notes setbacks of the traditional tendering model, and provides kind of theoretical support for establishing a new tendering model for universities and colleges and the related enterprises in China.
\end{abstract}

Keywords: New Circumstances; Universities and Colleges; Tendering Management; Innovative Thought DOI: http://dx.doi.org/10.26549/jetm.v2i2.738

A $\mathrm{t}$ present, there are some problems in the tendering model applied by universities and colleges in China. Thus, innovative efforts should be made, in order to meet the requirements of the advance of Chinese higher-education institutions under new circumstances and to create favorable conditions for them to secure progress in the fierce competition. The Chinese market economy model has constantly improved. However, new challenges have also come to the fore. Therefore, from the perspective of economic-management theories, this paper, proceeding from various problems and challenges encountered under new circumstances, aims to propose a feasible tendering model, which combines with the status quo of universities and colleges in China. As for the tendering management of universities and colleges in China, no obvious advantages can be found, and many undertak- ings are not performed in a professional manner. Besides, there is a lack of coordination for the departments participating in the related undertakings, and more efforts should be made to ensure that all the information on tendering is brought into the open. The paper focuses on such issues, and proposes a method for scientific tendering.

\section{The Tendering Management Mechanism of Universities and Colleges in China}

In our country, there is a lack of coordination for universities and colleges participating in various links of tendering-related programs. The tendering programs of universities and colleges in China are mainly confined to those on campus. However, due to the limited space on campus and few types of programs, new programs are rare to be found on campus. Most programs are related to the renovation, expansion or reconstruction of current programs.

Author's Information: Ze Zhou (1972-), Male, Born in Zhijiang, Hubei, the Han Nationality, Environmental Engineering, Engineer, Tendering Management

Corresponding Author: Ze Zhou, 51964289@qq.com 


\subsection{The Method of Tendering Management Mecha- nism of Universities and Colleges in China}

Currently, the tendering-focused management mechanism, adopted by Chinese universities and colleges is characterized with the government-managed model. As for the bidding model, there is no distinction between government-led projects and civil-imposed projects. Seen from the practical reality of the current tendering models across the globe, as for the management model, there is a fundamental difference between government-led projects and civil-imposed projects. Therefore, they are different in terms of the model of bidding and tendering. However, universities and colleges in China have not made a clear distinction during the tendering process. All the tendering-related projects should be conducted in a publicized tendering and bidding manner. First, an anticipated planning price for the tendering project (namely, the general price and the related requirements) should be proposed, and the tendering process should be brought into open. Then, those who propose the lowest price or the most feasible model of the project win the bid. However, for universities and colleges in China, there are still some problems related to bidding management in colleges and universities in China. Specific analysis will be made in the next section.

\subsection{The Status Quo of Tendering Management Mechanism of Universities and Colleges in China}

Currently, there are four major problems in the tendering management mechanism of universities and colleges in China. The specific analysis is as follows. Firstly, universities and colleges in China have not brought their advantages into full play in tendering projects. Due to the fact that universities and colleges are essentially public-funded, the construction projects and other types of projects managed by these institutions are essentially different from those managed by government agencies. The tendering programs of universities and colleges in China are mainly confined to those on campus. However, due to the limited space on campus and few types of programs, new programs are rare to be found on campus. Most programs are related to the renovation, expansion or reconstruction of current programs. The projects within universities and colleges are scattered, and the types are also complicated. Most of them relate to the reconstruction of teaching buildings or living areas. The projects of universities and colleges are targeted to students, and therefore the requirements for project quality are higher. Due to the fact that the standards of universities and colleges adopted in tendering are multifarious, it is fairly difficult to supervise the tendering process in China. This has affected the monitoring quality of tendering projects, as well as the moni- toring use of project funds.

Secondly, as for tendering projects of universities and colleges in China, the staff members involved are not professional. The professionalism of staff members involved, as well as their insight into the projects and the specific conditions of tendering market, will affect the tendering results. The projects of universities and colleges have higher requirements for engineering technologies, quality, duration, and payment. If the tendering team is not professional, the specific responsibilities, in case of accidents, will not be fully fulfilled. Thus, the whole project may be affected by some unqualified bidding enterprises engaged in the construction affairs. As for the lists related to the construction, if the tendering team cannot get a detailed picture of the related projects, the items displayed on the list may be omitted. In serious cases, the project will not be completed on time, or the team will fail to reach the required standards.

Then, in our country, there is a lack of coordination for universities and colleges participating in various links of tendering-related programs. There are certain annual limits for the purchasing budget, which accounts for a large proportion in the total budgets, of universities and colleges in China. Universities and colleges, as an important part of public-funded institutions in China, have many types of annual projects. Therefore, in general, the budget of one project fails to account for a large proportion. This requires universities and colleges to dovetail their strategies with each other for the coordination of budget needs, and, if possible, the budget for each department should be met. However, most of universities and colleges in our country have not reached a consensus on the project budget, which will expose certain impact on the tendering management of projects. The sufficient budget for tendering projects may affect the normal teaching activities. Therefore, as for universities and colleges, there are still some improvements needed in handling these issues.

Finally, during the tendering process, universities and colleges in China are still torn by such problems as insufficient sources of information and standardized documents, as well as procedures which are not transparent. This brings certain difficulties to the tendering process. Currently, the statistics of tendering information adopted by universities and colleges in China are merely used for the work done on the paper, with the aid of computers, and therefore, a complete system of tendering information has not been established. When they computers are used for the work done on the paper, the information on tendering is stored by means of computers, instead of paper version. That's all. This storage model of tendering information, traditional as it is, fails to handle the related 
information in a productive manner. Besides, it cannot provide scientific data on tendering affairs. The project is ridden with low efficiency. In addition, on the platform of tendering information adopted by Chinese universities and colleges in the tendering process, part of tendering information is merely put in place. However, the information on the whole tendering process fails to be shared in a detailed and public manner. This may bring prejudicial effects to the coordination of various departments involved in the tendering process.

1.3 Case Analysis of Tendering Management Mechanism of Universities and Colleges in China

Currently, most of the tendering models adopted by universities and colleges in China are traditional in essence. This paper makes a detailed analysis of the tendering management model for campus construction adopted by North China Electric Power University. The traditional campus-based project of North China Electric Power University heads the list of those projects of Chinese universities and colleges. As for the tendering links of campus construction, there are also some problems concerning the traditional model. The campus-based project of North China Electric Power University is mainly completed through external tendering. During the bidding process, the staff members involved are not professional, and the traditional tendering model is ridden with its non-transparent process of data collection, resulting in some loopholes for the enterprises engaged in the bidding business. There are some kinds of misconduct - external factors, for instance, human connections, play a significant role in the process of tendering, which should be strictly prohibited. In addition, the tasks are not performed by various departments in a scientific and coordinated manner during tendering, which may result in low efficiency and little progress in the related projects.

\section{Analyses on the Barriers to the Innovation of Tendering Management Mechanism of Univer- sities and Colleges in China under New Circum- stances}

Universities and colleges in China, as the main battlefield of tertiary teaching and learning, should boast their perfect systems of supervision and management for the tendering management mechanism. Nowadays, the government has increased its spending on the higher-education system. The projects launched by many universities and colleges are also increasingly complicated in type, which should be completed by professionally trained personnel. In addition, for the tertiary teaching and learning in universities and colleges, it's necessary to establish a reasonable tendering process and a sound management system.

\subsection{Requirements for the Reform of Higher-Educa- tion System}

The higher-education system adopted by China has gradually improved, and major universities and colleges nationwide, based on their enhanced soft strength, have renewed efforts in upgrading their hardware facilities. ${ }^{[1]}$ Universities and colleges of higher level will go to waste without hardware facilities, the construction of campus infrastructure, and the development of campus environment. Universities and colleges seeking their enhanced competence in education should renew their efforts in overhauling the old-fashioned structure, in order to meet the requirements of the education-system reform. Currently, the government has increased its spending on the higher-education system. The projects launched by many universities and colleges are also increasingly complicated in type, which should be completed by professionally trained personnel. In order to make full use of the funds channeled into the higher-education system, it's necessary to establish a system of tendering management, through which the truly competent people who are the most suitable for the projects and the professional team boasting the greatest efficiency will be selected.

\subsection{Requirements for the Independence of Depart- ments in Universities and Colleges}

In general, universities and colleges in China are not skillful in the tendering process. As a result, instructions and approvals from competent authorities are required. In spite of higher feasibility, such procedures are in low efficiency, due to a series complicated formalities and a lack of coordinative efforts among different departments. As for those time-demanding tendering projects, some delays may bring prejudicial effects to the development of universities and colleges, if competent authorities fail to make instructions in a timely manner. Therefore, major universities and colleges in China, while striving to find their own patterns of development, try hard to establish their independent departments for tendering-related affairs and to enhance their competence in decision-making in an independent manner. On the one hand, this gives more leeway for universities and colleges; on the other hand, it avoids the inconvenience caused by a series of cumbersome formalities of competent authorities which may exert harmful impact on tendering projects of universities and colleges. $^{[2]}$

\subsection{Requirements for the Standardized Tendering Process}

Universities and colleges in China, as the major part of public-funded institutions, should have their standardized process for tendering projects. The process is also available for other public-imposed management under- 
takings in our country or the tendering plans of infrastructure construction laid down by the government. Since currently universities and colleges in China enjoy a sound momentum, the types of projects are diversified, and the tendering projects are also complicated. If the tendering process is not clear-cut or standardized, some excellent bidders may fail to stand out in the competition, and some unqualified construction departments will win the bid instead. A standardized tendering process and a sound supervision system are of vital help to avoid such problems to the maximum extent, thus providing safe, reliable institutional guarantees for the bidding projects (for instance, related to campus construction) of universities and colleges in China.

\section{Innovation-Driven Ideas of Tendering Manage- ment Mechanism of Universities and Colleges in China}

The tendering tasks, which are not performed by a single department, require the coordination and cooperation of multiple departments. Thus, in order to yield fruitful results, the staff members in various departments should make concerted efforts. However, the deepened scope of network has exerted profound influence upon the restructuring and upgrading of many industries. Thus, there is no exception in the tendering management mechanism of universities and colleges in China. It's imperative for universities and colleges to strengthen their efforts in the centralized management of tendering and to make use of network resources in a rationale manner.

\subsection{Set up the Basis for Centralized Tendering}

The centralized management of tendering is conducive to equal opportunities for tendering provided by universities and colleges in China. Based on this, the tendering team is subject to rigorous scrutiny. ${ }^{[3]}$ As for the centralized management of tendering, first of all, an institution responsible for tendering must be established in universities and colleges. The institution should join in hands with the related legal departments and management departments in formulating a set of legal and reasonable plans of tendering management. The plans should include laws and regulations on the tendering process across the board, management-focused considerations, as well as measures of punishment. The plans should deal with such affairs as announcements issuance, organization of tendering activities, negotiation of tendering contracts, and signup of tendering contracts, so as to avoid problems arising from unclear tendering procedures. Secondly, the tendering management department should strictly carry out the tendering-related policies, adhere to the principle of openness and fairness, and strengthen their efforts in the management of personnel responsible for tendering affairs and the education on honesty and moral integrity. At the same time, they should be subject to strict scrutiny, so as to avoid any unfair tendering-related problems due to the corrupt administration. In addition, since the projects conducted by universities and colleges are multifarious, the staff members of the tendering department are required to classify the tendering projects in a rigorous manner. If possible, there should be uniform standards for the time of tendering start-up and completion, as well as the types of tendering projects, and some tendering projects should be performed in a uniform manner. This will maximize the efficiency of the tendering team, and reduce the costs. ${ }^{[4]}$

\subsection{Identify the Core Business in Which the Staff Members Specialize}

Professional tendering team serves as the core of the successful operation of tendering projects performed by universities and colleges in China. Firstly, based on the establishment of special tendering management departments, personnel with rich experience in tendering management and excellent overall qualities should be recruited. Seen from the experience acquired from the previous projects conducted by universities and colleges, the staff members in charge of tendering affairs should be armed with both a complete set of professional knowledge, good capabilities of teamwork and ideological coordination. The staff members should acquire a full set of professional knowledge, so as to avoid the professional homogeneity of the whole tendering team. If everyone in the team specializes in the same field or the same subject, the requirements on every front of tendering-related affairs cannot be met; secondly, it's necessary to enhance overall qualities of the contracted staff members in charge of tendering affairs. During the tendering process, it's of vital importance to coordinate the on-the-job training of special skills, through which the staff members will constantly broaden their horizon, enrich their knowledge and improve their competence, as well as accomplish their self-cultivation and accumulate a wealth of practical experience; finally, measures should be taken to enhance the service quality and raise the awareness of the staff members, for instance, performance evaluation. Accordingly, a set of scientific evaluation system of tendering should be established, through which the staff members in charge of tendering affairs are subject to appraisal and assessment. ${ }^{[5]}$

\subsection{Identify the Prerequisites for the Coordination among Different Departments}

The tendering projects of universities and colleges in China are not performed by a single department. Instead, they call for the cooperative efforts of multiple departments. Firstly, an independent tendering management department 
of universities and colleges should be established, in order to coordinate the related affairs of tendering. Secondly, the other related departments should join in hands with the tendering management department in various affairs. The detailed budget plan should be reported to the tendering management department. Then, the related staff members should lay down detailed documents, coordinate the tendering projects in a reasonable manner, and report to the university's management department for approval of documents and funds. ${ }^{[6]}$ Upon the approval, the tendering department should engage in a series of market analysis for further results, and obtain a detailed budget plan of tendering, so as to maximize the use of tendering-related funds; secondly, the tendering department should be subject to the scrutiny of universities and colleges and government agencies. Based on this, it can strengthen its efforts in the anti-corruption campaign, so as to eliminate misconduct during the tendering process which may affect the scientific decision-making and fairness of the tendering projects. ${ }^{[7]}$

\subsection{Means to Establish the System of Electronic Tendering}

Electronic tendering, as a new type of tendering model, aims at the documents issuance and the coordination of tendering affairs, by means of a new online platform. The details of the completed tendering projects will be publicized online, thus ensuring the transparency and fairness of the entire tendering process, and securing the scientific abundance of tendering affairs. ${ }^{[8]}$ During the process of implementation, firstly, a uniform tendering database of universities and colleges should be established, with the classified types of information on tendering included, so that the tendering department can access to the required documents and materials easily; secondly, the data on the tendering process should be disclosed, including the general introduction of the tendering department, the use of tendering funds, and the affairs to be paid attention to during the construction process; finally, upon the tendering results, the construction contract signed between the related department and the universities and colleges should be publicized in the database, thus achieving the openness and transparency of the tendering projects to the maximum extent. ${ }^{[9]}$

\section{Conclusion}

In summary, the tendering management is indispensable, against the backdrop of the constant development and expansion of universities and colleges in China. In order to enhance the efficiency of tendering affairs and to secure the rational use of funds, it's necessary to establish a professional tendering team, which is responsible for the coordination of various departments. Besides, a new type of electronic tendering platform should be established, with the aid of the Internet technologies, thus ensuring the centralized tendering model fairness and transparency. As a result, as for the innovation of tendering management mechanism for universities and colleges, positive results will be yielded. As for the innovation, it's also necessary to draw experience from the traditional tendering model and to combine it with the new tendering mode, so as to meet the needs of tendering management of universities and colleges in China to the largest extent.

\section{References}

[1] Chuntian Xia, Xiangming Ye, et al. Reflections on Strengthening the Standardized Bidding Management of Universities and Colleges in China[J]. Experimental Technology and Management. 2012(04): 201-202. (in Chinese)

[2] Honglu Zhang, Huaning Lv. Discussion on the Countermeasures for Preventing Nominal Contractors in the Infrastructure Tendering Projects of Universities and Colleges[J]. Journal of Guangxi University for Nationalities (Philosophy and Social Science Edition) 2014(12): 67-68. (in Chinese)

[3] Yuan Lu, Deqi Luo. Exploration of the New Tendering Model - "Three-in-one" for Construction Projects of Universities and Colleges[J]. Journal of Huazhong University of Science and Technology (Urban Science Edition) 2016 (09): 121-122. (in Chinese)

[4] Yong Liu. Research and Discussion on Logistics Management Model for Small-and Medium-sized Universities and Colleges[J]. SME Management and Technology. 2016(7): 23-24. (in Chinese)

[5] Yang Zang. The Application of Tendering Management in the Management of Universities and Colleges[J]. Economic \& Trade, 2016, 23(15): 168. (in Chinese)

[6] Hong An, Wenping Liao. Discussion on the Innovation of Self-tendering Management of Universities and Colleges from the Perspective of Internal Control[J]. Commercial Accounting, 2016, 20(09): 37-39. (in Chinese)

[7] Duanling Wu. Anti-corruption Campaign Based on Tendering Activities of Universities and Colleges[J]. Journal of Handan Polytechnic College, 2015, 28(01): 82-84. (in Chinese)

[8] Rui Wang, Xiaochun Shao. Business Expansion of Corporate-tendering Management and Consulting, Aimed at the Transformation and Development of Tendering Agencies[J]. Tendering \& Purchasing Management, 2014, 24(09): 29-30+38. (in Chinese)

[9] Chun Zhao. Research on the Innovation of Tendering Management Mechanism of Construction Projects Conducted by Universities and Colleges[J]. China Market, 2013, 16(30): 52-53. (in Chinese) 